University of Nebraska - Lincoln

DigitalCommons@University of Nebraska - Lincoln

Bureau of Sociological Research - Faculty

Publications

Bureau of Sociological Research (BOSR)

November 2003

\title{
Frustrated Fertility: Infertility and Psychological Distress Among Women
}

Julia McQuillan

University of Nebraska - Lincoln, jmcquillan2@Unl.edu

Arthur L. Greil

Alfred University

Lynn K. White

University of Nebraska - Lincoln, Iwhite3@unl.edu

Mary Casey Jacob

University of Connecticut Health Center

Follow this and additional works at: https://digitalcommons.unl.edu/bosrfacpub

Part of the Sociology Commons

McQuillan, Julia; Greil, Arthur L.; White, Lynn K.; and Jacob, Mary Casey, "Frustrated Fertility: Infertility and Psychological Distress Among Women" (2003). Bureau of Sociological Research - Faculty Publications.

13.

https://digitalcommons.unl.edu/bosrfacpub/13

This Article is brought to you for free and open access by the Bureau of Sociological Research (BOSR) at DigitalCommons@University of Nebraska - Lincoln. It has been accepted for inclusion in Bureau of Sociological Research - Faculty Publications by an authorized administrator of DigitalCommons@University of Nebraska - Lincoln. 


\title{
Frustrated Fertility: Infertility and Psychological Distress Among Women
}

\author{
Julia McQuillan, University of Nebraska-Lincoln ${ }^{1}$ \\ Arthur L. Greil, Alfred University ${ }^{2}$ \\ Lynn White, University of Nebraska-Lincoln ${ }^{3}$ \\ Mary Casey Jacob, University of Connecticut Health Center ${ }^{4}$
}

\begin{abstract}
Using a random sample of 580 Midwestern women, we test the hypothesis that women who have experienced infertility report higher psychological distress. Approximately one third of our sample reports having experienced infertility sometime in their lives, although the majority of the infertile now have biological children. Drawing hypotheses from identity and stress theories, we examine whether roles or resources condition the effects of infertility or whether its effects are limited to childless women. Infertility combined with involuntary childlessness (including biological and social) is associated with significantly greater distress. For women in this category, the risk of distress is substantial.
\end{abstract}

Keywords: infertility, involuntary childlessness, parenthood, psychological distress, stress.

1 Department of Sociology, University of Nebraska-Lincoln, 706 Oldfather Hall, Lincoln, NE 68588-0324 (Corresponding author-email jmcquillan2@unl.edu )

2 Division of Social Sciences at Alfred University, Olin Building 208B One Saxon Drive, Alfred, NY 14802

3 Department of Sociology, University of Nebraska-Lincoln, 736 Oldfather Hall, Lincoln, NE 68588-0324

4 Departments of Psychiatry and Obstetrics/Gynecology, University of Connecticut Health Center, 263 Farmington Avenue, Farmington, CT 06030-6305
As women postpone childbearing until later in life, a growing proportion of American women experience infertility. Estimates from a large national sample suggest that $10 \%-15 \%$ of nonsurgically sterile American women ages 15-44 experience current fertility impairment (Chandra \& Stephen, 1998). For some women, this impairment extends the period of time necessary for spontaneous conception, but others can conceive only with medical intervention or not at all.

The experience of infertility is an unwelcome interruption to those who expect parenthood to be a key identity and adult activity. Most people assume they can become parents when they are ready, and Greil (199 la) found that "the vast majority of both husbands and wives were taken by total surprise when they became aware of their infertility" (p. 72). Matthews and Matthews (1986) suggest that parenthood is so central to most people's identities that the infertile experience a real and stressful "transition to nonparenthood" despite the fact that no objective change in status occurs.

We draw from identity and stress theories to examine the consequences of fertility impairments for women's distress among a random sample of 580 Midwestern women. Although qualitative work and research on clinical samples supports the notion that 
infertility is a source of distress, the effect of infertility on distress has not been established in random samples of women not in the throes of treatment.

Conceptualizations of infertility vary across disciplines and studies. In this study, we use a measure of lifetime infertility. We use the term infertility interchangeably with subfecundity. Contrary to demographic use (where infertility means no live births), we use a medical definition of infertility as an inability to conceive after 12 months of unprotected intercourse. Our usage is similar to lay understanding of infertility as a problem in conception and does not imply childlessness. In fact, a large majority of women who have ever had an episode of infertility (our lifetime measure) now have biological children.

\section{Theoretical Background}

Stress occurs when people experience events or circumstances, called stressors, for which their coping resources are inadequate (Pearlin, Lieberman, Menaghan, \& Mullan, 1981). Stressors need not be events, but can also be nonevents or failures to achieve life goals or desired identities (Aneshensel, 1992). When situations external to individuals prevent them from achieving or maintaining a valued identity and when their behavior has little or no effect on the situation, the challenge to their identities is expected to cause stress. According to Burke (1991), such identity disruptions will result in higher levels of distress when the interruption is repeated or severe, when the identity in question is highly salient, and when the identity is one to which the individual is highly committed. Thoits $(1991,1999)$ also suggests that threats to salient identities are likely to lead to psychological distress. That the inability to have desired children is such a stressor is supported by its inclusion as an item in one of the standard measures of chronic stress (Turner \& Lloyd, 1995).

An individual's identity salience hierarchy is, in large part, formed in response to the expectations of others, both in face-to-face social relationships and in the larger social context. Thus, identity salience hierarchies are remarkably similar within a given society (Stryker, 1987). In American society, the attainment of parenthood is central to many people's identities and, among parents, is usually their most salient identity (Thoits, 1992). Children are viewed as providing core life meaning, social support, social integration, and, in later life, instrumental and social assistance (Burton, 1998), and few Americansmen or women - want to or expect to be childless (Thornton \& Young-DeMarco, 2001). Although not all adults, and not even all parents (Groat, Giordano, Cernkovich, Pugh, \& Swinford, 1997), embrace parenthood, we expect that difficulty in attaining the status of parenthood is distressing. Gendered expectations that motherhood should be an essential aspect of femininity make this role even more salient for most American women (Rothman, 1989).

Stress theory suggests that the degree of distress associated with failing to conceive will depend on resources and roles. We derive three possible relationships among resources, roles, and distress. We call the first possibility the resource buffering model. Stress theory suggests that people with more resources are better able to cope with a given stressor, and that stress is least evident among those with more advantaged statuses (Pearlin et al., 1981). In the specific case of infertility, however, Scritchfield (1995) argues that failure to conceive is particularly painful for women who have been successful in other aspects of their lives.

The second possibility is a general role-accumulation hypothesis based on Thoits's (1999) argument that a blocked identity or role will result in more distress for those with few alternate identities. This perspective suggests that individuals who occupy multiple roles will be protected from stress, whereas those with no children, no employment, or no spouse will be the most distressed. Thus the general role-accumulation hypothesis predicts that employment, motherhood, and marriage mitigate the consequences of being infertile.

The third possibility is a specification of the role accumulation hypothesis we call the master status model. This view builds on the observation that parenthood ranks high in the identity salience hierarchies of most Americans, independent of their other roles and resources. For women especially, parenthood may be considered a master status (Hughes, 1945) in the sense that motherhood casts its shadow over other statuses and permeates the performance of a wide range of social roles. A large body of scholarship testifies that it is difficult to separate motherhood from feminine identity, socially or personally (Ireland, 1993). If motherhood is a master status, then we expect infertility to be distressing only to women who want children but who remain childless. 
Ethnographic studies of the involuntarily childless report a sense of spoiled identity or stigma (Greil, 1991b), where childlessness becomes the master status that dominates their lives (Greil; Miall, 1985; Remennick, 2000). This research also suggests that it is the combination of childlessness and infertility that is distressing.

The master status argument does not imply that all women should or do want to be mothers or that motherhood is a central identity for all women. Motherhood has very different meanings for women in different social locations and personal circumstances (Arendell, 2000; Groat et al., 1997), and a small minority of fecund women voluntarily choose to be childless. Regardless of their choices or circumstances, however, decisions regarding motherhood remain central to women's experiences and identities, and the choice of childlessness still results in social stigma (Hays, 1996; Somers, 1993). Even among those with fertility impairments, recent advances in medical treatment mean that childlessness has elements of choice. Ironically, these choices may be yet another source of stigma and stress for women who do not choose to pursue medical treatment or to pursue it to its extreme (Letherby, 1999; Rothman, 1989). Despite the fact that treatment is not always successful or appropriate, parenthood is now assumed to be within the grasp of anyone who wants it badly enough. This expectation ignores many structural barriers to treatment such as geographic distance from treatment providers, the high cost of treatment, inflexible work schedules for medical visits, racism, and homophobia.

Our central hypothesis is that the social experience of infertility is a source of stress that results in prolonged elevated levels of psychological distress. We test to see whether roles or resources modify this effect or whether the experience of infertility is distressing only to women who are not mothers.

\section{Prior Empirical Work}

Ethnographic studies of infertile individuals describe feelings of distress, loss of control, social isolation, and stigma when couples try unsuccessfully to achieve pregnancy (Daly, 1988, 1999; Greil, 1991a; Matthews \& Matthews, 1986; Miall, 1985, 1986). These same studies make it clear that if the role blockage represented by infertility is distressing, treatment regimens may be a source of equal or greater distress. Infertility treatments are invasive, expensive, time-consuming, and emotionally draining. Treatment involves the repetitive raising and dashing of the hope of pregnancy, perhaps resulting in an increase in the saliency of parenthood identity and a heightened sense of distress in the face of the failure to attain parenthood (Dunkel-Schetter \& Lobel, 1991). Studies of treatment populations also suggest that infertility stress is associated with lower quality of marriage and general well-being (Abbey, Andrews, \& Halman, 1994; Wright, Allard, Lecours, \& Sabourin, 1989), especially for women.

When the infertile are compared with control groups, however, research yields mixed results. Systematic reviews of the literature reach dramatically different conclusions. Wright et al. (1989) conclude that the infertile are more psychologically distressed than the general population, whereas others (Dunkel-Schetter \& Lobel, 1991; Edelmann \& Connolly, 1998) conclude that the evidence is insufficient to support this assertion. Greil's (1997) comprehensive review of the literature concludes that most well-designed studies find that the infertile are more distressed than the fertile, but generally not in a clinically significant way.

Inconsistent findings from quantitative studies of infertility are attributable partly to methodological shortcomings. Most studies on the psychosocial consequences of infertility use clinic-based samples of treatment seekers. We are aware of only one study that uses a large random sample to compare women with and without infertility experience. Using the National Study of Family Growth, King (2003) demonstrated that women with current fertility impairment scored higher on a standard anxiety measure than women without such impairment regardless of treatment seeking.

Because many studies are small and drawn from a single clinic, inconsistent findings may well be an artifact of study design. In addition, the use of clinic samples confounds the consequences of treatment seeking, treatment itself, and fertility status. In the United States, it is estimated that only half of couples with infertility seek treatment (Chandra \& Stephen, 1998). Because non-treatment-seekers differ substantially from treatment-seekers on race and socioeconomic status (Berg \& Wilson, 1990; Wright et al., 1991), this is a potentially serious omission. Lowincome and minority women are likely to have more general stress (Ross \& Mirowsky, 1989; Williams, Takeuchi, \& Adair, 1992) and may experience infertility differently than women who are more socially and materially advantaged. Although King's (2003) study 
suggests that the higher levels of anxiety among the currently infertile are independent of treatment, the long-term effects of infertility on the general population of women remain an open question.

\section{Statement of the Problem}

Using a random sample of women ages 25-50, we assess whether women with lifetime infertility report greater psychological distress and whether the relationship between infertility and distress depends on role identities or resources. We use information about motherhood, employment, and relationship status to evaluate hypotheses about role accumulation, and information about education, income, and race/ethnicity to evaluate the resource buffering hypothesis. If women with more resources are less distressed, this will support the resource buffering hypothesis. If infertile women who are workers, wives, or mothers are less distressed than women without these roles, this will support the role accumulation hypothesis. If infertility is distressing only to the childless, we will conclude that the evidence favors a master status interpretation of infertility.

The lifetime prevalence measure of infertility that we use identifies women who have ever experienced infertility. Thus, we are assessing long-term consequences of infertility for most women, as opposed to short-term consequences that may be associated with treatment regimens or the shock of bad news. This is a conservative test of the hypothesis that infertility is distressing. It allows us to distinguish women whose infertility prevented them from having children from those who were able to surmount this obstacle. A weakness of this measure is that some women in our sample encountered infertility recently, whereas others experienced infertility 20 years ago. Although we cannot pinpoint the time of the infertility episode for all of the subfecund women, the correlation between women's current age and years since they first experienced infertility is strong $(r=.69)$ among those where the data are available (87\%). Thus age is a rough proxy for timing of the infertility episode, and we explore whether the effects of infertility on distress depend on age. A supplementary analysis focusing only on the infertile considers the effect of medical helpseeking. We include education, income, and nonHispanic White race/ethnicity as resources that may condition the response to infertility. Because prior research has demonstrated their correlation with distress (Schieman, Van Gundy, \& Taylor, 2001), we control age, subjective general health, and chronic health condition.

\section{Method \\ Sample}

We use a random sample of women ages 2550 from 12 states in the upper Midwest who interviewed in 2002. Households were selected through random digit dialing with an oversample of telephone numbers from Census tracts with large minority populations. When more than one eligible woman lived in the household, another random process selected the respondent. The overall response rate for this study was $63 \%$. This $63 \%$ response rate reflects two processes, an $80 \%$ likelihood of contacting a listed household and a $78 \%$ cooperation rate among contacted households. Cooperation is defined as completing the interview or completing a short screening interview that established ineligibility for the survey; that is, households with no women ages 25-50. We used up to 15 call-backs to reach a household resident and up to 15 additional calls to reach the designated respondent.

Comparison of this sample with Census data for the 12 states shows that the sample closely mirrors the population of women by age. As intended, the sample overrepresents African Americans: 15\% of the sample is African American compared with 10\% of women ages 25-50 in these states. Interviews were conducted only in English, but the sample matches the population at $4 \%$ Latina. As is usual with telephone surveys, the sample overrepresents well-educated women: $36 \%$ of the sample reported 4 -year college degrees, compared with $27 \%$ of women in the Census.

\section{Measurement}

Distress. The dependent variable is the sum of 20 items of the Center for Epidemiological Studies Depression scale (CES-D) used to measure depressive symptoms (Radloff, 1977). The CES-D is not a diagnostic instrument, but it is appropriate for a study in which explanation, rather than treatment, is the central focus (Hann, Winter, \& Jacobsen, 1999).

Infertility. We categorized women into three groups: no fertility problems, medically defined infertility (subfecundity), and other fertility problems. 
The subfecundity measure reflects current medical definitions of infertility. Women $(n=203)$ were coded as subfecund if they reported any of the following: (a) tried for longer than 12 months to conceive any of their pregnancies, (b) sought medical help to conceive any of their pregnancies, (c) ever tried to get pregnant for more than 12 months without success, or (d) ever had regular unprotected intercourse for more than a year without pregnancy.

The other fertility problems category includes 38 women who do not fit medical definitions of infertility but who encountered fertility problems that made us hesitant to classify them as not infertile. These women reported a wide variety of problems: their own or their partner's surgical sterilization (including voluntary sterilizations) definitely kept them from having children that they wanted, their doctor advised them not to have more children even though they wanted more (nine women who had a baby despite their doctor's advice are not counted here), or they felt that difficulty getting pregnant definitely kept them from having babies they wanted (although they met none of the criteria established for medically defined infertility). In a larger sample with more detailed information, each of these could be examined separately and more extensively. Rather than exclude these women from the analysis, we coded them as one category and included this as a control variable in the analysis.

Although miscarriages are not technically an infertility problem (because conception occurs), inability to carry a child to term can be as distressing or more distressing than failure to conceive, at least in the short term (Geller, Klier, \& Neugebauer, 2001). Miscarriage also has the same absence of a biological child outcome as infertility. Of the 43 women in our sample with two or more miscarriages, only 26 met the criteria for subfecundity, and three for other fertility problems. The remaining 14 women who had two or more miscarriages are included in the comparison category of women with no fertility problems. Preliminary analyses (available from J. M.) show that alternative coding of these 14 women has no effect on the results.

Resource variables. Education is measured as the number of years completed at the time of the interview. Family income was recorded in 13 categories ranging from 0 (no income) to 12 (\$100,000 or more). We use dollar equivalents of the midpoint of each category, reported in $\$ 10,000$ s to make the coefficients easier to read. The Expectation Maximization imputation procedure in SPSS imputed values for 40 cases $(7 \%)$ with missing data on income. Education and income are mean centered to reduce collinearity with the interaction terms. Race/ethnic status is coded 1 if the respondent reported race as White and ethnicity as non-Hispanic and 0 for all others.

Social roles. To test the role accumulation model, we included dummy variables to capture occupancy of the primary social statuses available to women: mother, spouse, and employee. Preliminary analyses explored the consequences of using a broad definition of motherhood (including those who had step, adopted, or foster children), rather than a biological definition. Although isolating the 30 women who had step, adopted, or foster children but not biological children had little effect on results, the centrality of biological parenthood to issues of infertility led us to code them separately. Biological motherhood is coded 1 if the respondent bore any children and 0 if not. Social motherhood is coded 1 if a woman without biological children reports an adoption, a stepchild to whom she is very close, or foster children (through a formal program or informally). The omitted category is women who have no biological or social children.

Previous research shows that distress scores differ between married and cohabiting women (Brown, 2000). Therefore union status is coded using two dummy variables that contrast currently married and currently cohabiting women with unpartnered women. Employment is coded 1 for women working 35 hours a week or more and 0 for women working less than 35 hours a week.

Because satisfactory roles may be more important than mere role occupancy, we also included dichotomous measures that assess whether respondents are satisfied role occupants. Maternal satisfaction is based on responses to a single statement, "I get a lot of satisfaction from my children." Maternal satisfaction is coded 1 (strongly agree) and 0 (all others, including not a mother). Relationship satisfaction is based on a 9-item scale $(\alpha=.87)$, identical for married and cohabiting respondents, that includes an overall satisfaction indicator plus questions about satisfaction with specific issues such as faithfulness, love and affection, and someone to do things with. From this scale we created a dummy variable coded 1 for the top third of the satisfaction scale and 0 
Table 1. Descriptive statistics for variables used in the analyses by fertility status.

\begin{tabular}{|c|c|c|c|c|c|c|}
\hline \multirow[b]{2}{*}{ Variables } & \multicolumn{2}{|c|}{$\begin{array}{l}\text { Comparison } \\
(n=339)\end{array}$} & \multicolumn{2}{|c|}{$\begin{array}{c}\text { Subfecund } \\
(n=203)\end{array}$} & \multicolumn{2}{|c|}{$\begin{array}{l}\text { Other Fertility Problems } \\
\qquad(n=38)\end{array}$} \\
\hline & M/Proportion & SD & M/Proportion & SD & M/Proportion & SD \\
\hline \multicolumn{7}{|l|}{ Distress } \\
\hline CES-D summary score & 9.20 & 6.69 & 11.26 & 9.52 & 14.56 & $9.88^{* * *}$ \\
\hline \multicolumn{7}{|l|}{ Control variables } \\
\hline Chronic health problem & .17 & & .27 & & .29 & ** \\
\hline General health $\left(4=\right.$ excellent $^{\mathrm{a}}{ }^{\mathrm{a}}$ & 3.27 & .68 & 3.04 & .77 & 2.84 & $.64^{* * *}$ \\
\hline Age $(25-50)^{a}$ & 37.84 & 6.96 & 38.76 & 6.82 & 40.34 & 6.46 \\
\hline \multicolumn{7}{|l|}{ Resources } \\
\hline Education in years $^{a}$ & 14.77 & 2.48 & 14.06 & 2.21 & 13.78 & $2.61^{* *}$ \\
\hline Family income (in $\$ 10,000 \mathrm{~s}$ ) a & 5.88 & 2.72 & 5.63 & 2.54 & 4.79 & 2.82 \\
\hline White, non-Hispanic & .81 & & .74 & & .76 & \\
\hline \multicolumn{7}{|l|}{ Roles } \\
\hline Mother & .80 & & .91 & & .95 & ** \\
\hline Biological mother & .77 & & .88 & & .90 & \\
\hline Social mother only & .06 & & .04 & & .08 & \\
\hline \multicolumn{7}{|l|}{ Wife/partner } \\
\hline Married & .66 & & .72 & & .55 & \\
\hline Cohabiting & .07 & & .05 & & .13 & \\
\hline Employee & .81 & & .77 & & .74 & \\
\hline High satisfaction from children & .61 & & .65 & & .63 & \\
\hline High relationship satisfaction & .48 & & .46 & & .50 & \\
\hline High job satisfaction & .29 & & .33 & & .26 & \\
\hline Sought any medical treatment & & & .39 & & .11 & $* *$ \\
\hline
\end{tabular}

Note: Random sample of Midwestern women ages 25 to $50(N=580)$.

${ }^{a}$ Mean centered for the multivariate analyses.

${ }^{* *} p<.01{ }^{* * *} p<.001$

for those with scores lower than the top third or who are not in a union. Job satisfaction is a single-item indicator, coded 1 (very satisfied) and 0 (less than very satisfied or not employed).

Control variables. Age is a continuous variable, mean centered. General health is measured by a singleitem indicator, "In general, would you say your health is excellent, good, fair, or poor?" The item is scored from 1 (poor) to 4 (excellent). This item is mean centered. Chronic health conditions are assessed by a single item, "Do you have any permanent health or physical condition that restricts your ability to move around or limits dressing, bathing, eating, working, or keeping house." This variable is coded 1 (yes) and 0 (no).

\section{Results}

\section{Descriptive Findings}

Over one third (35\%) of this sample report having experienced medically denned infertility at some point in their lives (subfecundity). This is higher than the $10 \%-15 \%$ estimates of current infertility generated by the National Survey of Family Growth (Chandra \& Stephen, 1998) but similar to other estimates of life-time prevalence (Greenhill \& Vessey, 1990; Page, 1989). Infertility is significantly associated with education, but it is not associated with race/ethnicity, age, income, employment, or marriage. Women with infertility experience are more likely to have borne children than those without infertility experience ( $92 \%$ vs. $82 \%)$, in part because infertility generally is not discovered until women try to have children. Roughly two thirds of the infertile reported primary infertility, that is, infertility before their first child was born. Table 1 presents descriptive statistics on all of the variables included in this analysis separately for the subfecund, the other fertility problems group, and the comparison group.

\section{Multivariate Analysis}

The multivariate analysis begins by regressing distress scores on infertility and the control variables. 
Because distress is a continuous variable, we use ordinary least squares regression. Subfecundity is significantly related to distress $(p=.02)$, as is the measure of other fertility problems (Table 2, Model 1). As expected from prior work on distress, older women and those in better health report lower distress.

Model 2 adds measures of roles and resources. Because our central hypotheses concern moderating effects of these variables rather than main effects, we add these variables in one step to conserve tabular space. Control for these variables reduces the main effect of subfecundity approximately $25 \%$, and it is no longer statistically significant. Net of the other variables in the model, education is the only resource variable related significantly to distress at the conventional .05 level. Turning to role measures, cohabitors have significantly higher distress than unpartnered women do. Satisfying role occupancy, especially marriage and employment, is significantly related to lower distress. This main effects analysis suggests that, after controlling for roles and resources, lifetime infertility has little effect on distress for the average woman. Other fertility problems, however, continue to be related significantly to distress.

The next step in the analysis is to examine the key interaction effects suggested by our theoretical review. Our first hypothesis was that the experience of infertility would be less distressing for women who occupy advantaged statuses (i.e., higher education, higher income, and majority status). To test this hypothesis, three multiplicative terms (education $\times$ subfecund, income $\times$ subfecund, and majority status $\times$ subfecund) were added one at a time to the model presented in Model 2 of Table 2. Only the income interaction was significant $(b=-0.54, p=.028)$. Subfecundity is more distressing for women with lower, rather than higher, family income.

The role accumulation hypothesis stipulated that distress would be greater among those with fewer roles. To test this hypothesis we created interaction variables for each of the social roles in the model (subfecund $\times$ social mother, subfecund $\times$ biological mother, subfecund $\times$ employed, subfecund $\times$ married, subfecund $\times$ cohabiting). Only subfecund $\times$ biological mother is significant. Consistent with the master status argument, infertile women who were biological mothers reported significantly lower distress than infertile women with no children.

As a way to capture women with careers (vs. jobs), we also tested education with a dummy vari- able indicating more than 16 years of education, and a three-way interaction of subfecundity, more than 16 years of education and employment. This interaction was not significant. To assess whether some combinations of roles buffered the effects of subfecundity, we needed several additional interaction terms. To simplify this part of the analysis, we combined types of mothers (biological and social) and types of relationships (married and cohabiting). Four higher-order interaction terms were created: subfecund $\times$ parent $\times$ employee, subfecund $\times$ parent $\times$ partner, subfecund $\times$ partner $\times$ employee, and subfecund $\times$ parent $\times$ employee $\times$ partner. These terms were added to a model already including the two-way interactions of subfecundity by roles. Addition of these higher order interactions did not add significantly to explained variance $\left(R^{2}\right.$ change $=.10$, $F[4,588]=1.85, p=.12$ ).

We also created interaction terms for the three measures of role satisfaction. Only the interaction between subfecundity and high relationship satisfaction was statistically significant $(b=$ $-2.91, p=.037)$. When entered into a model including the interaction of subfecundity with biological motherhood, however, this term was no longer significant.

The final interaction hypothesis we tested was whether the experience of infertility depends on age, which we treat as a proxy for time since the experience of infertility. We tested this interaction both as a continuous and as a nonlinear process. Whether assessed by a single term (subfecundity $\times$ mean-centered age) or by two terms (using dummy variables marking women 30 and under and women over 40), no significant interactions emerged. Although more extensive information on timing of infertility might produce a different result, this analysis suggests that the effect of subfecundity does not depend on women's current age.

Overall, we tested 12 central interactions, one for each of the roles and resources listed in Table 2 and one for age. Of these, three effects were significant at the .05 level, and only the modifying effects of biological parenthood and income appear to be independent. These two interaction effects are included in Model 3. In this model, the term for infertility now must be read as the effect of infertility among those with no children (biological or social) and mean income. Among subfecund women with no children, the effect of infertility on distress is significant $(p<.01)$, positive, and substantial. The stan- 


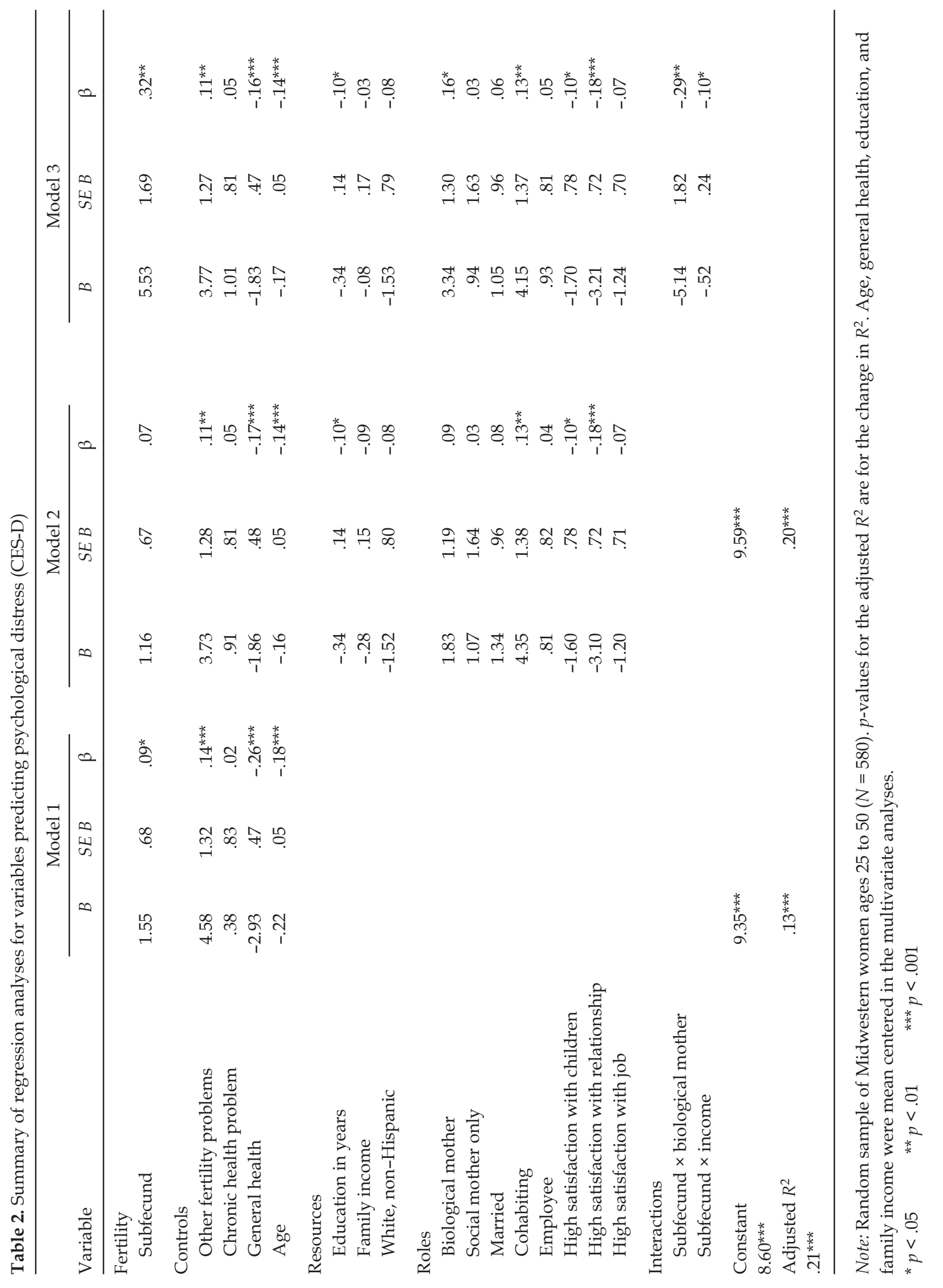




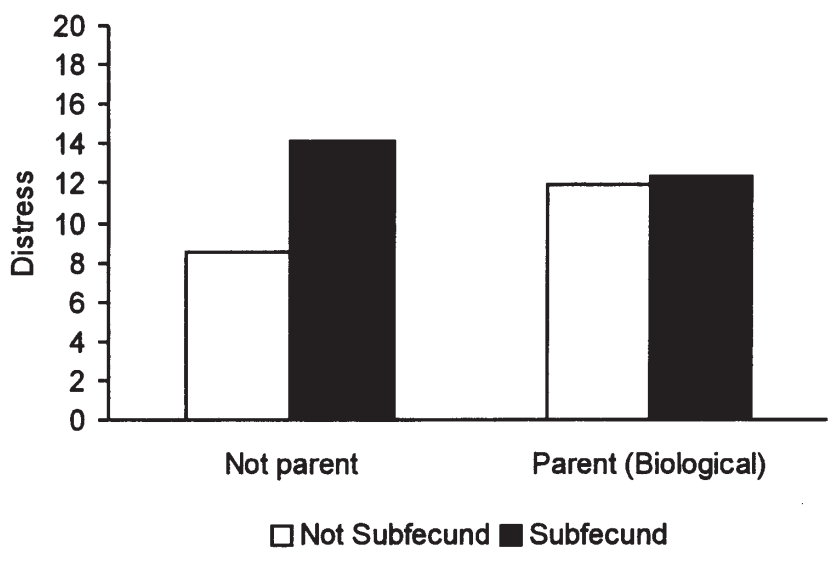

Figure 1. Mean predicted distress levels by infertility and parent status.

dard deviation for the CES-D measure in this sample is 8.13. Thus an unstandardized coefficient of 5.53 is equivalent to an effect size of .68. This relatively small group of women $(n=17)$ have mean CES-D scores of 13.35, more than four symptoms higher than the comparison group (9.20). This interaction is presented graphically in Figure 1 . As the figure makes clear, childlessness in the absence of infertility is not associated with greater distress. In fact, as prior studies suggest, childlessness by itself is associated with somewhat lower distress (McLanahan \& Adams, 1987).

The other significant interaction in Model 3 (Table 2) is for family income. As the resource buffering argument suggests, the distress reported by subfecund women is lower when income is higher (see Figure 2). This effect is statistically significant $(p=.02)$, but substantively modest. An increment of $\$ 10,000$ is associated with only a 0.5 reduction in distress among the subfecund, equivalent to half a symptom.

In a final step, we focused on the subsample of subfecund women and assessed whether distress was related to treatment seeking. Only 37\% of the women we categorized as subfecund had seen a physician about their condition, and even fewer had sought treatment. Whether assessed by a dummy variable indicating any treatment seeking or by more complex variables assessing levels of help seeking (diagnostics only, diagnosis and treatment, levels of treatment), we found no association between medical help seeking and psychological distress among the infertile (results available on request from J. M.).

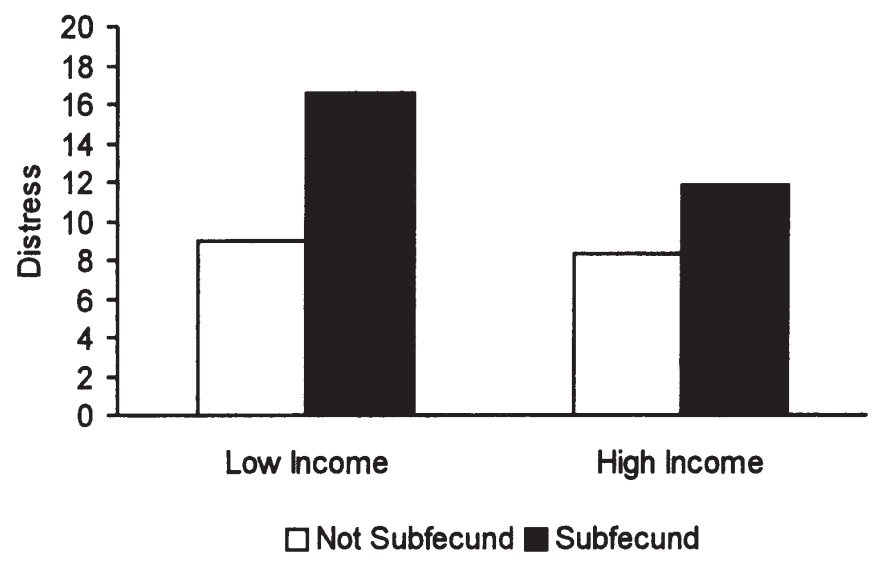

Figure 2. Mean predicted distress levels by fertility status and income level. Based on coefficients from Table 2, Model 3, and using mean values of all other variables in the model and income 1 standard deviation below and above the mean (approximately $\$ 30,000$ and $\$ 75,000 ; N=580$ ).

\section{Discussion}

Most previous studies of the psychosocial consequences of infertility use clinic-based samples, which limit generalizability and confound the effects of treatment and infertility. The present study addresses these limitations by using a random sample of women and a lifetime measure of infertility. Compared with women with no fertility problems, we find that infertility is associated with substantial and significant long-term psychological distress only for women with no children at all (social or biological). We did not find that education, race/ethnic status, marriage, cohabitation, employment, or age conditioned the effects of infertility. The subfecund were significantly, although modestly, less distressed when income was higher.

The results suggest that the long-term effects of infertility experience are not dependent on role accumulation and only modestly related to resources. Rather, as the master status argument suggests, infertility is associated with substantial long-term distress only for those who are not mothers. Among women who have neither biological nor social children, infertility is associated with substantively large and statistically significant higher levels of distress. The strong, long-term effect of motherhood denied supports an argument that frustrated attempts to achieve motherhood threaten a central life identity. Consistent with prior work that has used the master status argument to describe the experiences of involuntarily childlessness (Miall, 1985; Remennick, 
2000), childless women without fertility problems are not distressed by the absence of children. Thus it is not childlessness or infertility alone that predicts distress, but the combination; that is, involuntary childlessness. For these women, motherhood-or its absence-does appear to be a master status that casts a long shadow on well-being.

In assessing this evidence, it is important to challenge the implicit assumption that fertility impairment is equivalent to childlessness. In the 1995 wave of the National Survey of Family Growth, over $50 \%$ of the women with current fertility impairments had borne children already (Abma, Chandra, Mosher, Peterson, \& Piccinino, 1997). In our data, there is little overlap between childlessness and infertility: Only $8 \%$ of the subfecund are childless, and only $21 \%$ of the childless are subfecund. Infertility is only one part of the continuum of childlessness that spans a range of varying degrees of choice (Ireland, 1993; Koropeckyj-Cox, 2002).

Although a third of our small sample of women who are social but not biological mothers reports subfecundity (8 of 30), the numbers are too small for meaningful separate analysis. This is an important avenue for further research with a larger sample. The ability to separate forms of social motherhood (step, adopted, foster) and to identify women who become social mothers only after the experience of infertility will offer more complete insight into the long-term consequences of subfecundity.

This study provides a conservative test of the effects of infertility on distress in many ways. The medical definition of infertility includes some women who do not recognize their own infertility, who are not aware that 12 months of unprotected intercourse or even 12 months of unsuccessfully trying to conceive makes them infertile according to a medical standard. This measure also includes women whose infertility first occurred 10 or 20 years ago. Because $92 \%$ of the women who are categorized as infertile have borne children, our measure is weighted heavily by women who managed to bear children despite having low fertility. On the other side of the ledger, some of the women we categorized as fertile are young women who have not yet tested their fertility. Given these qualifications and the relatively small sample, it is remarkable that we have identified infertility as a significant predictor of distress for involuntarily childless women.

It is noteworthy that the women who reported other fertility problems are significantly more dis- tressed than the omitted category with no fertility problems. Although this small group of women $(n=38)$ has a mixture of problems, a plurality have sterilization regret, a condition estimated to affect a quarter of women who have voluntary tubal ligations (Chandra, 1998). It is not surprising that regret and distress are associated significantly, but the magnitude of the association is remarkable. Women who now say that their own surgery (whether voluntary or involuntary) prevented them from having the children they wanted had a mean distress score of $18.00(n=17)$. This is above the conventional cutoff score (16.0) for clinical depression. It would require a larger sample than we have to examine the component parts of other fertility problems and the circumstances under which they are more or less distressing, but this is obviously an important issue for future research.

Among the subfecund, $37 \%$ had sought some form of medical treatment. None of the treatment variables we considered had a significant association with levels of psychological distress. This suggests that the distress of infertility is not limited to treatment seekers or to the rigors of treatment. These results are consistent with King's (2003) study using a different sample and different measures. Thus we have more confidence in our finding that distress due to infertility is not limited to those undergoing treatment.

Although we have controlled for many of the most likely alternative predictors of distress-that is, social roles, role satisfaction, resources, and two measures of general health-these cross-sectional findings must be regarded as tentative. Studies in the last decades generally refute the psychogenic argument that distress causes infertility (Greil, 1997), but we cannot ignore the possibility that causality runs both ways without longitudinal studies that assess women prior to the experience of infertility. A larger sample that incorporates a prospective panel would resolve some of these issues, but future research also needs to move forward substantively in two ways. First, it should consider broader definitions of involuntary childlessness, such as the absence of a male partner. Second, it should examine the effects of infertility on men. Prior work suggests that men are less distressed by infertility than women, a finding not accounted for solely by their lower likelihood of being subjected to invasive therapies (Jordan \& Revenson, 1999). One way to untangle the question of the gendered nature of parenthood - that is, the difference between motherhood 
versus a generic identity of parenthood - is to assess whether blocked parental identities have the same consequences for men and women.

\section{Note}

We wish to thank David R. Johnson, Laurie Scheuble, Naomi Lacy, and Danelle de Boer, members of the team that designed the larger study of which this is a part. The University of Nebraska provided essential funding.

\section{References}

Abbey, A., Andrews, F. M., \& Halman, J. L. (1994). Psychosocial predictors of life quality: How are they affected by infertility, gender, and parenthood? Journal of Family Issues, 15, 253-271.

Abma, J. C., Chandra, A., Mosher, W. D., Peterson, L. S., \& Piccinino, L. J. (1997). Fertility, family planning, and women's health: New data from the 1995 National Survey of Family Growth (Vital and Health Statistics, Series 23, No. 19). Washington, D.C.: U.S. Government Printing Office, pp. 1-114.

Aneshensel, C. S. (1992). Social stress: Theory and research. Annual Review of Sociology, 18, 15-38.

Arendell, T. (2000). Conceiving and investigating motherhood: The decade's scholarship. Journal of Marriage and the Family, 62, 1192-1207.

Berg, B. J., \& Wilson, J. F. (1990). Psychiatric morbidity in the infertile population: A reconceptualization. Fertility and Sterility, 53, 654-661.

Brown, S. L. (2000). Stress and critical transitions: The effect of union type on psychological well-being: Depression among cohabitors versus marrieds. Journal of Health and Social Behavior, 41, 241-255.

Burke, P. J. (1991). Identity processes and social stress. American Sociological Review, 56, 836-849.

Burton, R. P. D. (1998). Global integrative meaning as a mediating factor in the relationship between social roles and psychological distress. Journal of Health and Social Behavior, 39, 201-215.

Chandra, A. (1998). Surgical sterilization in the United States: Prevalence and characteristics, 1965-1995 (Vital and Health Statistics, Series 23, No. 20). Washington, D.C.: U.S. Government Printing Office.

Chandra. A., \& Stephen, E. H. (1998). Impaired fecundity in the United States: 1982-1995. Family Planning Perspectives, 30, 34-42.

Daly, K. (1988). Reshaped parenthood identity: The transition to adoptive parenthood. Journal of Contemporary Ethnography, 17, 40-66.
Daly, K. (1999). Crisis of genealogy: Facing the challenges of infertility. In H. I. McCubbin, E. A. Thompson, A. I. Thompson, \& J. Futrell (Eds.), The dynamics of resilient families (pp. 1-40). Thousand Oaks, CA: Sage.

Dunkel-Schetter, C., \& Lobel, M. (1991). Psychological reactions to infertility. In A. Stanton \& C. DunkelSchetter (Eds.), Psychological adjustment to infertility: Perspectives from stress and coping research (pp. 29-57). New York: Plenum.

Edelmann, R. J., \& Connolly, K. J. (1998). Psychological state and psychological strain in relation to infertility. Journal of Community and Applied Social Psychology, 8, 303-311.

Geller, P. A., Klier, C. M., Neugebauer, R. (2001). Anxiety disorders following miscarriage. Journal of Clinical Psychiatry, 62, 432-438.

Greenhill, E., \& Vessey, M. (1990). The prevalence of subfertility: A review of the current confusion and a report of two new studies. Fertility and Sterility, 54, 978-983.

Greil, A. L. (1991a). Not yet pregnant: Infertile couples in contemporary America. New Brunswick, NJ: Rutgers University Press.

Greil, A. L. (1991b). A secret stigma: The analogy between infertility and chronic illness and disability. Advances in Medical Sociology, 2, 17-38.

Greil, A. L. (1997). Infertility and psychological distress: A critical review of the literature. Social Science and Medicine, 45, 1679-1704.

Groat, H. T, Giordano, P. C-, Cernkovich, S. A., Pugh, M. D., \& Swinford, S. P. (1997). Attitudes toward childbearing among young parents. Journal of Marriage and Family, 59, 568-581.

Hann, D., Winter, K., \& Jacobsen, P. (1999). Measurement of depressive symptoms in cancer patients: Evaluation of the center for epidemiological studies depression scale (CES-D). Journal of Psychosomatic Research, 46, 437-443.

Hays, S. (1996). The cultural contradictions of motherhood. New Haven: Yale University Press.

Hughes, E. C. (1945). Dilemmas and contradictions of status. American Journal of Sociology, 50, 353-359.

Ireland, M. S. (1993). Reconceiving women: Separating motherhood from female identity. New York: Guildford Press.

Jordan, C., \& Revenson, T. A. (1999). Gender differences in coping with infertility: A meta-analysis. Journal of Behavioral Medicine, 22, 341-358.

King, R. B. (2003). Subfecundity and anxiety in a nationally representative sample. Social Science and Medicine, 56, 739-751. 
Koropeckyj-Cox, T. (2002). Beyond parental status: Psychological well-being in middle and old age. Journal of Marriage and Family, 64, 957-971.

Letherby, G. (1999). Other than mother and mothers as others: The experience of motherhood and nonmotherhood in relation to 'infertility' and 'involuntary childlessness.' Women's Studies International Forum, 22, 359-372.

Matthews, R., \& Matthews, A. M. (1986). Infertility and involuntary childlessness: The transition to nonparenthood. Journal of Marriage and the Family, 48, 641-649.

McLanahan, S., \& Adams, J. (1987). Parenthood and psychological well-being. Annual Review of Sociology, 13, 237-257.

Miall, C. E. (1985). Perceptions of informal sanctioning and the stigma of involuntary childlessness. Deviant Behavior, 6, 383-403.

Miall, C. E. (1986). The stigma of involuntary childlessness. Social Problems, 33, 268-282.

Page, H. (1989). Estimation of the prevalence and incidence of infertility in a population: A pilot study. Fertility and Sterility, 51, 571-577.

Pearlin, L. I., Lieberman, M. A., Menaghan, E. G., \& Mullan, J. T. (1981). The stress process. Journal of Health and Social Behavior, 22, 337-356.

Radloff, L. (1977). The CES-D scale: A self-report depression scale for research in the general population. Applied Psychological Measurement, 1, 385-401.

Remennick, L. (2000). Childless in the land of imperative motherhood: Stigma and coping among infertile Israeli women. Sex Roles, 43, 821-843.

Ross, C. E., \& Mirowsky, J. (1989). Explaining the social patterns of depression: Control and problem solving-Or support and talking? Journal of Health and Social Behavior, 30, 206-219.

Rothman, B. K. (1989). Recreating motherhood: Ideology and technology in a patriarchal society. New York: Norton.

Schieman, S., Van Gundy, K., \& Taylor, J. (2001). Status, role, and resource explanations for age patterns in psychological distress. Journal of Health and Social Behavior, 42, 80-96.
Scritchfield, S. A. (1995). The social construction of infertility: From private matter to social concern. In J. Best (Ed.), Images of issues: Typifying contemporary social problems (2nd ed., pp. 131-146). Hawthorne, NY: Aldine de Gruyter.

Somers, M. D. (1993). A comparison of voluntarily childfree adults and parents. Journal of Marriage and the Family, 55, 643-650.

Stryker, S. (1987). Identity theory: Developments and extensions. In K. Yardley \& T. Honess (Eds.), Self and identity: Psychological perspectives (pp. 89-103). New York: Routledge \& Kegan Paul.

Thoits, P. A. (1991). On merging identity theory and stress research. Social Psychology Quarterly, 54, 101-112.

Thoits, P. A. (1992). Identity structures and psychological well-being: Gender and marital status comparisons. Social Psychology Quarterly, 55, 236-256.

Thoits, P. A. (1999). Self, identity, stress, and mental health. In C. S. Aneshensel \& J. C. Phelan (Eds.), Handbook of the sociology of mental health (pp. 345-368). New York: Kluwer Academic/Plenum.

Thornton, A., \& Young-DeMarco, L. (2001). Four decades of trends in attitudes toward family issues in the United States: The 1960s through the 1990s. Journal of Marriage and Family, 63, 1009-1037.

Turner, R. J., \& Lloyd, D. A. (1995). Lifetime traumas and mental health: The significance of cumulative adversity. Journal of Health and Social Behavior, 36, 360-376.

Williams, D. R., Takeuchi, D., \& Adair, R. K. (1992). Socioeconomic status and psychiatric disorder among blacks and whites. Social Forces, 71, 179-194.

Wright, J., Allard, M., Lecours, A., \& Sabourin, S. (1989). Psychosocial distress and infertility: A review of controlled research. International Journal of Fertility, 34, 126-142.

Wright, J., Duchesne, C., Sabourin, S., Bissonnette, F, Benoit, J., \& Girard, Y. (1991). Psychosocial distress and infertility: Men and women respond differently. Fertility and Sterility, 55, 100-108. 